УДК 330.34:339.924

Гурова В.О.

канд. эконом.наук, доцент

Донецкий национальный университет (2. Винница)

\title{
ТЕОРЕТИЧНІ АСПЕКТИ ГЛОБАЛЬНИХ МІЖСИСТЕМНИХ ТРАНСФОРМАЦІЙ ПОСТІНДУСТРІАЛЬНОГО ПОРЯДКУ
}

\author{
ТЕОРЕТИЧЕСКИЕ АСПЕКТЫ ГЛОБАЛЬНЫХ МЕЖСИСТЕМНЫХ \\ ТРАНСФОРМАЦИЙ ПОСТИНДУСТРИАЛЬНОГО ПОРЯДКА
}

\section{THEORETICAL ASPECTS OF GLOBAL INTERSYSTEM TRANSFORMATION OF POSTSNDUSTRIAL ODER}

У роботі представлено аналіз теоретичних поглядів представників різних течій економічної теорії на категорію «трансформація»; підкреслено, щчо глобальні трансформачії є об'єктом міждисииплінарних досліджень: як етап всесвітньої історії, як сегмент міжнародної політики, як предмет сочіологї̈ та сочіальної теорії; зроблено акцент на визначенні джерел та об'єктів трансформації економічної системи, з точки зору інформаційної та науково-технологічної складової; при розгляді трансформацій різних економічних $i$ сочіальних систем в різних цииклах їх динаміки, проведено аналіз типології трансформащій, щзо дозволило виділити міжсистемні і внутришньосистемні трансформачії; зроблено висновок, що теорії міжсистемних трансформацій економічних систем логічно взаємопов'язані з конщепціями постіндустріального, постекономічного, постринкового суспільства $і \in$ взаємодоповнюючими, оскільки постідустріальні трансформачії впливають на різноманітнісфери діяльності економічних суб'єктів (технологічну, соціальну, політичну, культурну, фінансову та ін.).

Ключові слова: трансформаційний процес, міжсистемні і внутрішньосистемні трансформації, постіндустріальні трансформації.

В работе представлен анализ теоретических взглядов представителей различных течений экономической теории на категорию «трансформация»; подчеркнуто, что глобальные трансформации являются объектом междисциилинарный исследований: в качестве этапа всемирной истории, как сегмент международной политики, как предмет сочиологии и социальной теории; сделан акцент на определении источников и объектов трансформачии экономической системы, с точки зрения информачионной и научнотехнологической составляющей;при рассмотрении трансформаций различных экономических и социальных систем в различных циклах их динамики, проведен анализ типологии трансформаций, что позволило выделить межсистемные $и$ внустрисистемные трансформации; сделан вывод, что теории межсистемных трансформаций экономических систем логически взаимосвязаны с концепциями постиндустриального, постэкономического, пострыночного общества и являются взаимодополняющцими, поскольку постидустриальные трансформации затрагивают различные сферы деятельности экономических субъектов (технологическую, социальную, политическую, культурную, финансовую и проч.).

Ключевые слова: трансформационный процесс, межсистемные ивнутрисистемные трансформации, постиндустриальные трансформации. 
The paper presents an analysis of the theoretical views of representatives of the various currents of economic theory on the category of "transformation"; was stressed that the global transformation are the subject of interdisciplinary research: as a stage of world history, as a segment of international politics, as the subject of sociology and social theory; emphasis was made on the identification of sources and objects of the economic system's transformation, in terms of information and scientific and technological content; considering the different economic and social systems' transformations in the various cycles of their dynamics typology of transformations was analyzed, which allowed to highlight interconnections and intra-system transformation; concluded that the theory of intersystem transformation of economic systems are logically linked to the of post-industrial, post-economic, postmarket concepts, since postindustrial transformation affecting different areas of economic subjects' activity (technological, social, political, cultural, financial, and others).

Keywords: transformation process, intersystem and intra-system transformation, postindustrial transformation.

Введение. Современный мир переживает сложный период радикальных трансформаций, неоднозначных по своим последствиям, затрагивающих основы экономических систем различного уровня, проявляющихся в снижении их системной устойчивости и сопровождающихся кризисными явлениями. Обострение противоречий, хаотичность экономической динамики и нарастание волны глобальных кризисов на рубеже тысячелетий обусловлены закатом индустриальногоэкономическогостроявнаиболееразвитыхстранах,исчерпание м имеющегосяпотенциалароста,неспособностьюнайтиадекватныеответына вызовы нового века, новой эпохи и осуществить переход к развитию на качественно новой основе.

Феномен глобальных трансформаций, их резонансный характер и возможные риски в течение последних десятилетий привлекают внимание исследователей различных направлений: философов, социологов, экономистов, экспертов, изучающих международные отношения, политологов, культурологов, антропологов и представителей многих других дисциплин.

Так, глобальные трансформации рассматриваются с разных позиций: как этап всемирной истории, как сегмент международной политики, как предмет социологии и социальной теории. Сформировалось специализированное направление глобальных исследований, аустойчивый интерес к теме глобальных трансформаций обеспечивается усилиями известных учёных.Проблематика трансформации экономических систем основывается на вопросах общей экономической теории. Проблемы формирования, развития, смены экономических систем исследовались в работах многих ученых на протяжении длительного периода времени. Особенно острый интерес к проблеме трансформации экономическихсистемвозниквпоследнеевремя в связи с усилением взаимосвязи национальных экономик, ускорением интеграции их в мировую экономику,увеличениемчислафактороввоздействиянапроцессфункционирова ния экономической системы и ее изменения.

Проблемы трансформации развитых экономических систем нашли 
отражение в концепции постиндустриального общества Д. Белла, нового индустриального общества Дж. Гэлбрейта, информационного общества И. Масуди и Ф.Махлупа, технотронного общества 3. Бжезинского, электронного общества М. Маклюэна, программируемого капитализма М. Естербрукса, электронно-цифрового общества Д. Тапскотта, программированного общества А. Турена, информационного, сетевого общества М. Кастельса и др.

Постановка задания. Целью данного исследования является анализ теоретических взглядов на экономическую категорию «трансформация» и анализ теоретико-методологических основ межсистемных трансформаций в условиях постиндустриальных изменений.

Результаты исследования. Источником современного понимания трансформации экономическойсистемыможно считать исследованияК.Маркса о производственныхотношениях капиталистического общества и воздействия на их развитие кооперации, мануфактуры, фабрики и процессов обобществления производства. Также больший интерес для исследования трансформации экономической системы имеют идеи смешанной экономики .А.Вагнер (социально-правовая школа) В. Зомбарт (новая историческая школа) обосновали положение о сочетании различных (частного и государственного) секторов экономики, разных форм собственности. Эти идеи получили развитие в направлениях институционализма, теорияхнео- и посткейнсианства, неоклассическом синтезе, разнообразныхсоциал-реформистскихтеориях.

Среди школ и течений экономической теории, наибольший вклад в определение источниковиобъектов трансформации экономической системы, с точки зрения информационной и научно-технологической составляющей, внесли труды Д. Белла, С. Глазьева, Э. Денисона, П. Друкера, Д. Кендрика, С. Кузнеца, Р. Солоу, Дж. Стиглица, Я. Тинбергена, Э. Тоффлера, Ф. Хайека, Й. Шумпетера и другие ученые.

Э. Тоффлер [8], используя понятие «глобальная трансформация общества», под трансформацией понимает значительные качественные изменения в развития общества, причем каждое изменение является не продолжением развития общества в заданном направлении, а его радикальным преобразованием. Следовательно, процесс трансформации необходимо характеризовать с точки зрения радикальности или глубины качественных изменений экономической системы.

В общем смысле, трансформация - преобразование, видоизменение. В общественных науках это понятие получило значительное распространение в последние десятилетия и используется для характеристики новейших процессов, связанных с структурными изменениями экономических систем. Трансформация трактовалась как процесс преодоления существенных элементов старого порядка и формирования нового качественного состояния экономической системы [4].

При анализе литературных источников приходим к выводу, что в настоящее время понятие «трансформация» толкуется достаточно широко и 
применяется ко всем типам существенных изменений основных структур и систем. При этом среди зарубежных и отечественных ученых нет единства в понимании сущности трансформации экономических систем. В самой общей трактовке этот процесс выражается как изменение, преобразование вида, формы, существенных свойств того или иного объекта, видоизменение социальных институтов и структур, что порой сопровождается их коренным обновлением.

Философский словарь определяет трансформацию как взаимно стимулирующие изменения моделей социального действия, с одной стороны, и функционирования социальных институтов, связанного с умышленным, целенаправленным воздействием номинальных установок (формальных норм, процедур или правил) - с другой.

Украинская исследовательница Н. Гражевская трактует это понятие с разных точек зрения: трансформация в широком смысле - всеобщая форма развития экономических систем, связанная с их эволюционными и революционными преобразованиями, постоянными переходами от устойчивого к неустойчивому состоянию и наоборот; трансформация в узком смысле - внутренняя составляющая эволюционного процесса, связанная с нарушением равновесия и постепенности на пути обновления системы в ходе скачкообразных качественных преобразований [3].

Известный российский экономист Т. Заславская предоставляет такое определение этого экономического явления. Трансформационный процесс постепенное, относительно мирное, но вместе с тем глубокое и относительно быстрое преобразование социальной природы общества, которое обусловлено прежде всего не внешними факторами, а внутренними потребностями системы [6].

Российские ученые Б. Кузык и Ю. Яковец рассматривают трансформацию в контексте ее эволюционного развития как объективный процесс, суть которого заключается в необходимых конкретно-исторических преобразованиях (зависимых не только от экономического сознания, когда деятельность человека подчиняется оценке экономических критериев). Проявление субъективного состоит в реализации объективного процесса хозяйствующими субъектами на основании правил, норм, базирующихся на национальных традициях и на основе общественных и индивидуальных оценок этого процесса. Трансформация социально-экономической системы, рассматриваемая в контексте ее революционного развития, - это не только объективный, но и субъективно-волевой процесс, отличающийся особой значимостью выбора концепции и модели развития, осознанностью, необходимостью выбора и принятия решения [7].

Экономисты ордолиберальной школы понятие «трансформация» трактуют в рамках исследования хозяйственных порядков. Изменения, которые испытывает экономическая система, они оценивают с точки зрения изменения ее структуры. Однако одни из них под трансформацией понимаюткоренное преобразование экономической системы в результате изменений егоструктуры, порядка системы (эндогенная трансформация) или 
сознательных действий людей(экзогенная трансформация) [2], другие считают достаточнымлюбую замену даже отдельных составляющих, которые конструируют порядок, на другие составляющие, благодаря которым старый порядок (или егоотдельная сфера) заменяется новым [1].

Глубина и продолжительность трансформации не одинаковы для различных экономических и социальных систем и для различных циклов их динамики. Одни трансформации краткосрочные и проходят сравнительно легко и безболезненно; другие имеют более радикальный характер и требуют серьезных изменений в структуре, содержании и формах экономических и социальных отношений; третьи, наиболее глубокие, болезненные и длительные, могут протекать десятилетиями и даже веками и приводят к наиболее существенным изменениям в структуре общества при изменении сверхдолгосрочных, вековых циклов.Соответственно, можно предложить классификацию трансформации по различным признакам.

По сфере действия:

- общесистемные

(B

структуре

цивилизаций, социодемографические);

- в структуре и динамике: (энерго-экологические, технологические, экономические, геополитические, социокультурные).

По сфере распространения:

- точечные (в рамках отдельного коллектива, предприятия);

- локальные (в пределах отдельной местности);

- региональные (в пределах отдельного региона страны);

- национальные (в рамках национальной экономики страны);

- межстрановые (между группой взаимосвязанных стран или локальных цивилизаций);

- глобальные (охватывающие все мировое пространство).

По глубине и продолжительности:

- краткосрочные, текущие;

- среднесрочные (при изменении среднесрочных циклов);

- долгосрочные (при изменении циклов Н. Кондратьева);

- более долгосрочные (при изменении столетних цивилизационных циклов);

- глубокие (при изменении тысячелетних, суперисторичных циклов) [9].

В дополнение к вышепредложеной классификации, также выделяют системные и межсистемные трансформации. Системные трансформации возникают из-за неспособности целого адекватно реагировать на воздействия внешней среды за счет значительной неоднородности воспроизводственных звеньев и снижения адаптивных свойств. Такие трансформации, прежде чем образуется новая система с качественно другими свойствами, обязательно проходят через порог неустойчивости, неопределенности предыдущей системы. Системные трансформации ряд авторов называют макротрансформациями (трансформациями в масштабах всей системы).

Межсистемные (надсистемные, глобальные) трансформации означают 
кардинальные изменения в мирохозяйственных процессах вследствие действия определенных факторов, например, мирового финансового кризиса и тому подобное. Надсистемные трансформации трактуют как проходящие за пределами отдельной экономической системы. Тесно переплетаясь, системные и межсистемные (глобальные) трансформации принципиально поразному влияют на развитие конкретных стран [6].

В рамках анализа теоретических взглядов, посвященных проблемам трансформации развитых рыночных систем, был исследован вопрос соотношения внутри ситемных и межсистемных трансформаций. Проблема социально-экономических преобразований развитых стран рассматривается в экономической литературе достаточно противоречиво: исследованиям, подтверждающим существенные качественные изменения свойств и характеристик рыночной капиталистической системы, противоречат не менее объективные и обоснованные исследования, авторы которых принципиально отрицают характер указанных трансформаций.

Сторонники концепций межсистемных трансформаций развитых экономических систем основываются на гипотезах о способах, путях и формах возникновения постиндустриального, постэкономического, пострыночного общества. По мнению российской исследовательницы Г.Ивлевой, указанные научные разработки активизировались в 70-80-е годы $\mathrm{XX}$ ст. и сейчас получили широкое распространение в экономической мысли, засвидетельствовав некоторые качественные изменения в современных рыночных системах [5]. Так, например, Э. Тоффлер в труде «Метаморфозы власти. Знание, богатство и сила на пороге XXI века» (1990) пишет о перспективе преодоления рыночных отношений и становления «трансрыночной» постэкономической цивилизации. Определение новой эпохи как теряющей рыночные признаки, приведены в труде П. Друкера «Посткапиталистическое общество» (1995). Такой же позиции придерживается Д. Белл, автор классического труда «Грядущее постиндустриальное общество» (1995). Российский ученый В. Иноземцев в труде «За пределами экономического общества» (1998) обосновывает перспективу становления «постэкономической цивилизации» и т.д.

Сторонники концепции внутрисистемных трансформаций развитых рыночных экономик трактуют указанные преобразования как естественноэволюционные изменения экономической системы, обусловленные логикой ее развития и направлены на преодоление внутренних ограничений. По их мнению, указанные изменения образовываются путем сложного процесса наслоения новых социально-экономических отношений на уже существующие и способствуют обогащению природы системы, не меняя логики и цели ее развития. При этом считается, что продолжительность таких социально-экономических трансформаций, сосуществование и интеграция новых и старых форм позволяют четко очертить качественные преобразования лишь после их конечной реализации [3].

На наш взгляд, на современном этапе развития мирохозяйственных связей, мы являемся свидетелями трансформаций постиндустриального 
порядка. Несомненным является тот факт, что данные трансформации являются межсистемными, поскольку охватывают различные сферы деятельности человека - технологическую, социальную, политическую, культурную, финансовую и др.. Глобальные постиндустриальные трансформации современности предположительно найдут свое отражение в следующем: производственные изменения (реконструкция сетей разработчиков технологий, провайдеров и пользователей, а также их взаимосвязь с соответствующими поставщиками финансовых услуг); социальные изменения (изменения в социальной среде могут создавать спрос на инновации, а могут препятствовать распространению новых технологий); технологические изменения (систематическое взаимодействие технологий требует их взаимосоответствия, которое приобретает главенствующее значение для обеспечения возрастающей отдачи от масштаба производства).

\section{Литература:}

1. Bohnet Armin, Ohly Claudia. Zum gegenwartigen Stand der Transformationstheorie / A. Bohnet, C. Ohly // Zeitschrift fur Wirtschaftspolitik. - 1992. - №41. - p. 27-49.

2. Анализ экономических систем: основные понятия теории хозяйственного порядка и политической экономики/ [Т. Вэльш, Х.-Г. Крюссельберг, Г. Ляйпольд и др.]; под ред. А. Шюллера и Х.-Г. Крюссельбе-рга. - 6-е изд., доп. и испр. - М.: Экономика, 2006. - $346 \mathrm{c}$.

3. Гражевська H.I. Економічні системи епохи глобальних змін: Монографія: К. : Знання, 2008. - 431 с.

4. Закономерности и перспективы трансформации общества: Материалы к V Междунар. Кондратьевскойконф.: В 3 т. / Под ред. Ю.В. Яковца. - М.: МФК, 2004

5. Ивлева Г. Трансформация экономической системы: обзор концепций и контуры общей теории // Общество и экономика. - 2003. - № 10. - С. 7-40

6. Кирилюк Є. М. Понятійний апарат досліджень трансформації економічних систем / С. М. Кирилюк // Економіка та підприємництво: зб. наук. праць молодих учених та аспірантів / М-во освіти і науки України, ДВНЗ "Київ. нац. екон. ун-т ім. В. Гетьмана"; відп. ред. С. І. Дем'яненко. - 2011. - Вип. 26. - С.14-25.

7. Кузык Б.Н., Яковец Ю.В. Цивилизация: теория, история, диалог, будущее. T.1. - М: Институт экономических стратегий, 2006.

8. Тоффлер Е. ТретяХвиля/ ЕлвінТоффлер; пер. 3 англ. А. Свса; ред. пер. Шовкун. - К.: Вид. дім«Всесвіт», 2000. - 475 с.

9. Яковец Ю. В. Глобальные экономические трансформации XXI века / Ю. В. Яковец. - М.:Экономика, 2011. - 382 с. 